\title{
Sex Differences in Affective Responses to Homoerotic Stimuli: Evidence for an Unconscious Bias Among Heterosexual Men, but not Heterosexual Women
}

\author{
Amanda L. Mahaffey, M.A., ${ }^{1,2}$ Angela Bryan, Ph.D., ${ }^{1}$ and Kent E. Hutchison, Ph.D. ${ }^{1}$
}

Received February 25, 2004; revisions received June 25, 2004 and August 24, 2004; accepted October 30, 2004

Antigay bias is a well-documented social problem among heterosexual men, though heterosexual women display a lesser tendency toward this bias. Startle eye blink has been established as a valid measure of the affective component of antigay bias in heterosexual men. In the current study, a sample of 91 heterosexual women and 87 heterosexual men were exposed to a variety of sexual photographic stimuli accompanied by startle probes. Heterosexual men who expressed more bias against gay men using a social distance measure (i.e., discomfort with being in close quarters with a gay man) displayed a startle response consistent with greater negative affect (e.g., fear and disgust) toward gay male stimuli, while those with less self-reported antigay bias did not display a physiological bias against gay men, and none of these men showed a relationship between bias against lesbians and physiological responses while viewing lesbian images. There were no such physiological manifestations of antigay bias in heterosexual women while viewing lesbian or gay male images, even among those who self-reported such bias. It appears that heterosexual women do not tend to have the same affective response toward homosexuals that some heterosexual men experience.

KEY WORDS: antigay bias; homophobia; affect; startle eye blink; sex differences.

\section{INTRODUCTION}

Antigay bias is a well-documented social problem among men. Women, on the other hand, appear much less likely to show antigay bias. Some researchers have argued that women do show antigay bias, but that their bias is against lesbians exclusively (Kyes \& Tumbelaka, 1993); however, the bulk of research in this area has found antigay bias to be, for the most part, a male phenomenon (Hansen, 1982; Herek \& Capitanio, 1999; Johnson, Brems, \& Alford-Keating, 1997; Kite \& Whitley, 1998; Kunkel \& Temple, 1992; Larsen, Reed, \& Hoffman, 1980; Yang, 1998). Johnson et al. (1997) reported that women, compared to men, had a less negative response to gays and lesbians with regard to their own level of

\footnotetext{
${ }^{1}$ Department of Psychology, University of Colorado, Boulder, Colorado.

${ }^{2}$ To whom correspondence should be addressed at Department of Psychology, UCB 345, University of Colorado, Boulder, Colorado 80309-0345; e-mail: amanda@psych.colorado.edu.
}

discomfort while being close to them, and that women tended to be more responsive to the civil rights of gays. Men, compared to women, reported more discomfort around gays, less willingness to grant human rights, and held less of a belief that homosexuality has a genetic basis.

It is generally theorized that these sex differences are attributable to gender-role beliefs and how adherence to traditional gender roles influences social status (cf. Kite \& Whitley, 1996; Whitley, 2001). Men are thought to place more importance on traditional gender norms than are women (e.g., Spence \& Hahn, 1997; Twenge, 1997), presumably because men have more to lose by violating and more to gain by adhering to these norms.

While not a correlate of antigay attitudes (i.e., beliefs about homosexuals), hyper-gender-role orientation (Mosher \& Sirkin, 1984) has also been shown to predict antigay behavior (i.e., verbal or physical actions taken against homosexual individuals; Whitley, 2001). This is evidence that one's own gender-role orientation plays a role in the tendency to act in a biased manner 
toward gay men and lesbians. Whitley (2001) argued that "homosexuality would present a strong threat to the self-concepts of people who are highly invested in traditional gender roles" and that the link between one's own gender role and behavior toward others is "a form of self-reaffirmation, demonstrating the magnitude of their rejection of homosexuality by engaging in antisocial behaviors" (p. 713). However, in Mosher and Sirkin's (1984) sample, men were still more likely than women to engage in antigay behaviors over and above gender role beliefs and hyper-gender-role orientation. Thus, it is possible that there is a more sex-specific component unique to men's reactions to gay men, perhaps an automatic response beyond fully conscious attitudes. An alternate, though related explanation is offered by Kimmel (1997), in which he described homophobia as a direct function of masculinity, such that to be a "real man," one must be homophobic, particularly toward gay men.

Antigay attitudes consist of three components: $\operatorname{cog}$ nitive, behavioral, and affective (Van de Ven, Bornholt, \& Bailey, 1996). The cognitive and behavioral components have been the focus of the majority of studies of antigay bias and these components are typically studied using self-report methods. Participants tend to willingly selfreport unsupportive social and political attitudes toward homosexuals (i.e., cognitive component) and, to some extent, participants will self-disclose previous gay-bashing experiences or display prejudice toward homosexuals (i.e., behavioral component); however, affect is somewhat less tangible, as emotions are not always conscious events (cf. Clore, LeDoux, Zajonc, Davidson, \& Ekman, 1994), and thus individuals might not always be fully aware of the negative affect that they may experience when face-to-face with a homosexual individual. Thus, the affective component of antigay bias may not be entirely measurable by self-report methods. Though prior research has documented that women are significantly less likely than men to experience the cognitive or behavioral aspects of bias against gay men and lesbians, it is unclear whether they experience the affective component in the same way as do men. One possibility is that women do not experience the same negative affective response toward same-sex homosexuals found among some men.

Past research has shown some success at measuring the affective component of antigay bias physiologically. Shields and Harriman (1984) measured heart rate while participants viewed sexual slides. Increased heart rate was observed in some homophobic participants, yet did not occur in any of the non-homophobic participants. One problem with these findings is that heart rate detects physiological arousal, but does not provide affective valence. Adams, Wright, and Lohr (1996) measured penile tumescence in homophobic and non-homophobic male participants using penile plethysmography. Sexual arousal was measured while participants watched erotic videos of sex between a man and a woman, sex between two women, and sex between two men. In this study, while all participants displayed arousal to the heterosexual and lesbian films, only homophobic males displayed objective sexual arousal when viewing gay male erotic videos. These data provide physiological evidence of Herek's (1987) "defensive function" of sexual prejudice, which he described as an affective reaction whereby one is threatened by homosexuality based on fears and uncertainty about one's own sexuality or gender conformity. Notably, physiological studies that have been conducted in this area have used only male participants, specifically because antigay bias is found to be more common among men (e.g., Kite \& Whitley, 1998). Consequently, the physiological underpinnings of the possible emotions surrounding antigay bias in women remain untested.

Startle eye blink has been used to successfully detect positive and negative affective responses (Blascovich, 2000; Lang, 1995). A recent report has shown that startle eye blink can detect implicit race bias and is an ideal conjunction between social psychological and neuroscientific approaches to measuring implicit bias by gauging one's affect (Amodio, Harmon-Jones, \& Devine, 2003). The startle response is a primitive, defensive reflex to a brief, intense stimulus, usually a $100 \mathrm{db}, 50 \mathrm{~ms}$ burst of static. Previous studies have demonstrated that the startle response is increased or potentiated by stimuli that evoke a negative affective response (e.g., a picture of a gun-shot victim) and decreased or inhibited by stimuli that evoke a pleasant affective response (e.g., a picture of kittens) or appetitive stimuli (e.g., nude females; cf. Lang, 1995). The startle response has been associated with sexually provocative stimuli in humans in two prior reports (Koukounas \& McCabe, 2001; Koukounas \& Over, 2000). One of these reports found that erotic stimuli attenuated the startle response but that the startle response was negatively correlated to physiological and subjective sexual arousal (Koukounas \& McCabe, 2001). These two studies suggest that exposure to sexual stimuli decreases the startle response in humans. The startle response is also useful in the study of fears or phobias such that objects of fears or phobias elicit greater startle in phobic or fearful individuals than in individuals not afraid of those objects (Hamm, Cuthbert, Globisch, \& Vaitl, 1997; Sabatinelli, Bradley, Cuthbert, \& Lang, 1996). Finally, the startle response has recently been shown to predict accurately automatic affective reactions to particular groups of 
people, such as those of a particular race (Amodio et al., 2003).

Similarly, we have conducted two studies of men in which we found startle eye blink to be a reliable measure of the affective component of antigay bias (Mahaffey, Bryan, \& Hutchison, 2005). In these studies, we compared participants' responses on an explicit paper-and-pencil measure of comfort level around homosexual individuals to their startle magnitude while viewing nude or seminude photographic stimuli of individual men, individual women, gay couples, lesbian couples, and heterosexual couples. We used a measure of Social Distance Toward Gay Men and Lesbians (Gentry, 1986) as our explicit measure. In essence, this measure taps the "fear of being in close quarters with a homosexual individual" aspect of Weinberg's (1973) original definition of homophobia. A significant relationship was established between explicit antigay bias on the social distance measure and implicit antigay bias using startle eye blink, such that the more disturbed a participant was by social contact with a gay man, the greater their startle magnitude (i.e., more negative affect) toward photographs of nude men and nude gay couples. This new evidence lays the groundwork for further studies of affective antigay bias using startle eye blink methodology.

The aim of the current study was to replicate our earlier findings with men and to determine whether these physiological patterns can be observed in women as well. If the automatic negative affect observed in some of the men in our previous studies is observable in women, women who express greater discomfort with being in close quarters with lesbian women will show greater startle magnitude (i.e., more negative affect) toward lesbian stimuli. We predicted, however, based on previous results of studies of the cognitive and behavioral components that women would not show this automatic affective response toward lesbians or toward gay men, and thus, affective antigay bias is perhaps related to men's attitudes more than women's attitudes.

The primary hypotheses were as follows: in accord with our previous research, we predicted that, for male participants, physiological affective reactions to viewing nude or semi-nude gay men would depend on levels of self-reported prejudice toward homosexuals. In other words, the greater self-reported discomfort with social contact with gay men reported by participants, the greater the expected magnitude (and thus, the more negative the affective reaction) of the startle response. On the other hand, we predicted that for female participants, there would be no relationship of self-reported antigay bias to startle magnitude toward any of the stimulus categories.

\section{METHOD}

\section{Participants}

Participants were 227 undergraduate men and women (112 women and 115 men) who agreed to participate in exchange for credit for an introductory psychology class. Forty-nine of these participants were eventually excluded from the analysis due to (1) technical difficulties with the startle recording equipment $(n=12)$, (2) participants displaying a startle response at a level below that which is distinguishable from random noise $(n=26)$, (3) participants not completing all parts of the experimental session $(n=6)$, or (4) participants reporting a homosexual orientation $(n=5)$ according to the Kinsey scale (Kinsey, Pomeroy, \& Martin, 1948). The final sample included 178 (91 women and 87 men) heterosexual participants (88\% Caucasian, 3\% Hispanic/Latino, 6\% Asian-American, $1 \%$ African-American, and $1 \%$ NativeAmerican) ranging in age from 18 to 32 years with a mean age of 19. Most reported a Christian Protestant affiliation or having no religion.

\section{Measures}

Measures consisted of a paper and pencil questionnaire. The measure of interest was the Social Distance Measure of Homophobia (Gentry, 1986) and it was embedded in the context of a number of attitude measures meant to serve as filler items. There are two subscales to this measure, one being Social Distance to a Gay Man ( $k=8, \alpha=.94)$ and the other being Social Distance to a Lesbian $(k=8, \alpha=.93)$. These subscales measure the social distance with which one is comfortable between oneself and a gay man or lesbian, and were developed to assess affective reactions toward homosexual men and women. This is in contrast to other well-known measures of antigay bias (e.g., Herek's (1988) Attitudes Toward Lesbians and Gays, Hudson \& Rickett's (1980) Index of Homophobia), which primarily target the cognitive component (e.g., "the idea of male homosexual marriages seems ridiculous to me") or focus on the civil rights of gay men and lesbians, or measure a combination of components. Since the focus of our line of inquiry was exclusively the affective component of antigay bias, and the Gentry (1986) measure has been found to be a reliable predictor of the startle response in men (Mahaffey et al., 2005), we determined that the continued use of such a measure that tapped this affective reaction was crucial to our analyses. There are eight items for each target group (i.e., gay man and lesbian) which are identical for each target group with the exception of the terms "gay man" or 
"lesbian." Item examples are: "I would be uncomfortable at a party where a gay man (lesbian) was present" and "It would bother me to live in the same house as a lesbian (gay man)." Both male and female participants were asked to respond to each of the 16 attitude statements using a 7-point Likert scale with 1 being "entirely disagree" and 7 being "entirely agree." Responses to items within each scale were averaged to determine a participants' score for that measure.

We also collected demographic information including age, ethnicity, religious affiliation, and degree of religiosity. Finally, we assessed sexual orientation using the Kinsey Scale, a single-item Likert-type scale assessing sexual orientation with entirely heterosexual at one end of the continuum and entirely homosexual at the other (Kinsey et al., 1948).

Photographic stimuli consisted of six affectively neutral stimuli (e.g., an electrical outlet) drawn from the International Affective Picture System (IAPS; Center for the Psychophysiological Study of Emotion and Attention, 1994). ${ }^{3}$ Each picture was chosen based on its published normative data. In addition, there were 6 photographs of gay male couples, 6 of lesbian couples, and 6 of heterosexual couples, taken from the public domain. The individuals shown in the photographs were either nude or semi-nude and romantically or sexually engaged in some way (e.g., kissing, fondling), though in the interest of decency, they do not depict actual penetration. All sexual stimuli depicted Caucasian couples so that ethnicity of the stimuli would not act as a confound.

\section{Procedure}

All procedures were reviewed and approved by a university-level internal review board (IRB). Participants each attended an individual experimental session lasting approximately one hour. The experimenter described the study to the participant as a method of assessing feelings about pictures by observing brainwaves. The experimenter explained all questionnaires and physiological measures and answered any questions. The experimenter and the consent form also let participants know that they would be viewing sexual images, and that if this made them uncomfortable, they could decline to participate. Participants read and signed IRB-approved informed consent documents. Each participant then completed all paper-and-pencil questionnaires.

Participants were then monitored for startle response via two $4 \mathrm{~mm} \mathrm{Ag-Ag} \mathrm{Cl}$ surface electrodes placed under

${ }^{3}$ IAPS numbers: (neutral stimuli) 5520, 6150, 7090, 7207, 7217, and 7235 . the left lower eyelid, $20 \mathrm{~mm}$ apart, over the orbicularis oculi muscle. In addition, a ground electrode was placed on the forehead. The skin beneath the electrodes was cleaned with an alcohol-saturated cotton swab immediately prior to electrode placement in order to lower impedance levels. The startle-eliciting stimulus was a $105 \mathrm{~dB}$, broadband noise that was $50 \mathrm{~ms}$ in duration. All auditory stimuli were administered to participants via headphones. Participants were instructed to observe a computer screen for the presentation of the photographs. To control for the effects of habituation across trial types, the order of presentation was randomized for each participant. Participants viewed each new slide for $5000 \mathrm{~ms}$, and the startle probe occurred $4000 \mathrm{~ms}$ after slide onset. This was deemed an ideal latency interval for our purposes due to recent evidence by Amodio et al. (2003) that long-latency startle eye blink (e.g., $4000 \mathrm{~ms}$ ) is adequate for indexing automatic affective race bias. Between each slide, the computer screen remained blank for a randomly generated variable interval, ranging from 18 to $22 \mathrm{~s}$, in order to clear any emotion associated with the previous image. Presentation of the slides was automated and the participants were unable to modify the presentation pace. The EMG signal was sampled at $1000 \mathrm{~Hz}$ and was filtered with a bandwidth of $28-500 \mathrm{~Hz}$.

For normative reasons, after acquisition of the startle data in response to all 24 slides, participants then viewed the same 24 slides again in the same order while responding to a single-item measure about their subjective affective valence on a 9-point Likert scale for each photograph. Participants were asked, "How happy are you right now, ranging from 1 = "very unhappy, sad, annoyed" to $9=$ "very happy, elated."

\section{RESULTS}

\section{Sex Differences in Social Distance}

We conducted a 2 (Participant Sex: Male or Female) $\times 2$ (Target Type: Gay Men or Lesbians) analysis of variance (ANOVA) on the two continuous measures of social distance. In these analyses, target type was a within-subjects factor. There was a significant Sex $\times$ Target Type interaction, $F(1,178)=95.64, p<.001$, such that male participants had significantly more antigay bias toward gay male targets and women had significantly more antigay bias toward lesbian targets (see Table I).

To examine the simple effects of sex of participant on explicit judgments of antigay bias, two regression equations were estimated. In one, social distance toward 
Table I. Differences Between Men and Women in Social Distance Toward Gay Men and Lesbians

\begin{tabular}{lrr}
\hline \multicolumn{1}{c}{ Participant Sex } & $M$ & \multicolumn{1}{c}{$S D$} \\
\hline Social Distance to Gay Men & & \\
$\quad$ Men & 2.52 & 1.36 \\
$\quad$ Women & 1.48 & .80 \\
Social Distance to Lesbians & & \\
$\quad$ Men & 1.63 & .82 \\
$\quad$ Women & 2.14 & 1.46 \\
\hline
\end{tabular}

Note. Absolute range, 1-7.

lesbians was the criterion and in the other social distance toward gay men was the criterion. Sex of participant was the predictor in both equations. There was a significant effect of sex of participant on social distance toward lesbians $(B=.22, p=.003)$, such that women were more biased than men against being in close proximity to lesbians. There was also a significant effect of sex of participant on social distance toward gay men $(B=-.42$, $p<.001)$, such that men showed more bias than women against gay men. Finally, we examined the effect of whether participants were judging opposite-sex or samesex targets. Two regression equations were estimated: one where the criterion was judgments about same-sex targets (i.e., men judging gay men and women judging lesbians) and one where the criterion was judgments about opposite-sex targets. In both equations, sex of participant served as the predictor. When judging same-sex targets, men showed marginally more antigay bias than women $(B=-.13, p=.06)$, but when judging oppositesex targets, there was no sex difference $(B=-.10$, $p=.19)$.

\section{Startle Eye Blink Patterns}

Startle magnitude toward each of the six photographs within each of the four categories of visual stimuli was averaged within participants. A 2 (Sex) $\times 4$ (Stimulus Type: Gay Men, Lesbians, Heterosexuals, or Neutral) ANOVA with repeated measures on Stimulus Type yielded a main effect for Stimulus Type, $F(3,570)=25.8, p<.0001$. Posthoc within-subjects pairwise comparisons showed that reactions to gay male stimuli were different from reactions to lesbian stimuli, $F(1,178)=7.78, p<.01$, and marginally different from reactions to heterosexual stimuli, $F(1,178)=3.69, p=.06$, although the reactions to heterosexual stimuli did not differ from reactions to lesbian stimuli, $F(1,178)=.23, p=.63$. See Table II for means and standard deviations for each stimulus category.
Table II. Startle Magnitude Means (Measured in Volts) for Each Stimulus Category as a Function of Sex

\begin{tabular}{llll}
\hline \multicolumn{1}{c}{ Stimulus Type } & Participant Sex & $M$ & $S D$ \\
\hline \multirow{2}{*}{ Neutral } & Men & .734 & .49 \\
& Women & .922 & .68 \\
\multirow{3}{*}{ Gay Male } & Combined & .830 & .60 \\
& Men & .652 & .45 \\
\multirow{3}{*}{ Heterosexual } & Women & .786 & .63 \\
& Combined & .721 & .55 \\
\multirow{4}{*}{ Lesbian } & Men & .642 & .48 \\
& Women & .746 & .63 \\
& Combined & .695 & .56 \\
& Men & .646 & .49 \\
& Women & .714 & .60 \\
& Combined & .681 & .55 \\
\hline
\end{tabular}

\section{Relationships Between Antigay Bias and Startle Eye Blink}

For each participant sex, a regression equation was estimated in which social distance toward same-sex homosexual couples and startle toward neutral images served as the predictors and startle eye blink toward same-sex homosexual images served as the criterion (see Table III). In order to minimize the influence of individual differences in overall startle reflex, startle response to neutral images was added as a covariate in each regression model.

In accord with our hypotheses, female participants showed no significant effects of social distance toward lesbians on startle eye blink toward lesbian images, $B=.01$, ns. A significant main effect relationship was established between men's social distance toward gay men and startle magnitude following the presentation of gay male couples. In accord with our main hypothesis, men who scored higher on the social distance toward gay men

Table III. Standardized Regression Coefficients for the Relationships Between Attitudes and Startle Eye Blink (measured in volts) Toward Homoerotic Images, Controlling for Individual Differences in the Startle Response

\begin{tabular}{clcc}
\hline & $\begin{array}{c}\text { Participant } \\
\text { Sex }\end{array}$ & $\begin{array}{c}\text { Startle toward } \\
\text { Gay Couples }\end{array}$ & $\begin{array}{c}\text { Startle toward } \\
\text { Lesbian Couples }\end{array}$ \\
\hline Model & & & \\
Social Distance & Men & $.15^{*}$ & \\
to Gay Men & Women & .05 & \\
Social Distance & Men & & -.04 \\
to Lesbians & Women & & .01 \\
\hline
\end{tabular}

$* p<.01$. 
measure showed greater startle magnitude toward images of gay male couples, $B=.15, p=.01$.

We then estimated the interaction between sex and social distance toward same-sex homosexuals in predicting startle magnitude toward same-sex homosexual targets. The main variables of interest in this analysis were sex of participant, social distance toward samesex homosexuals, and their interaction. In forming the interaction term, social distance was mean deviated, and the mean deviated version of the variable was also entered as the main effect. To control for extraneous sources of variance in startle toward same-sex homosexuals, startle toward neutral images, social distance toward oppositesex homosexuals, and the interaction of sex of participant and social distance toward opposite-sex homosexuals were added as control variables. We did this because in general there may be individual differences in willingness to express prejudiced attitudes. We wanted to examine the effects of same-sex antigay bias over and above any such generalized attitude. Over and above the effects of the control variables, there was a main effect of sex, $B=-.08, p=.04$, such that men had higher startle magnitude toward gay men than women had toward lesbians. Also consistent with our prior analyses, there was a main effect of social distance toward same-sex homosexuals, $B=.15, p=.003$, such that those who reported greater discomfort with interacting with a samesex homosexual tended to exhibit greater startle response toward images of homosexual couples of their own sex.

The interaction of sex of participant and samesex social distance was marginal, $B=-.09, p=.08$, but consistent with our hypothesis. As can be seen in Fig. 1, men who expressed greater discomfort around homosexual men had higher startle responses toward images of gay male couples. This effect was much weaker for women.

To probe the interaction, additional regression models were estimated to test the effect of social distance for each sex (see Fig. 1). The coefficient for the relationship between social distance and startle toward same-sex homosexual targets was significant for men $(B=.13$, $p=.02)$, but not for women $(B=.01$, ns). Thus, for women, their reports of discomfort around lesbians had no relationship to their startle toward images of lesbian couples, whereas for men, discomfort with social contact with homosexual men showed a significant relationship to startle response toward photographs of gay male couples.

It might be the case that our findings could be explained by women having a disjunction between their objective and subjective affective responses. This has been the case in research on sexual arousal responses (cf. Brody, Laan, \& Van Lunsen, 2003). ${ }^{4}$ To examine this possibility, we analyzed the relationship of subjective reports of affective valence and startle response to each of our sexual stimuli categories in order to compare the relationship of subjective to objective affective response in men versus women. For each category, we regressed startle response on subjective valence in response to viewing the pictures in that category, sex of participant, and their interaction. We found that for heterosexual stimuli, there was no relationship between subjective valence and startle for either sex (no main effect for subjective valence, $B=.007$, ns, and the interaction was also not significant; $B=.12, \mathrm{~ns})$. For gay male and lesbian stimuli, however, there was a strong positive relationship between subjective valence and the startle response, but only for women. For gay male stimuli, the sex $\times$ subjective valence interaction was marginal $(B=.48, p=.07)$ and for lesbian stimuli the interaction was significant $(B=.66$, $p=.004)$. The coefficient for the relationship between valence and startle toward lesbians for men was not significant $(B=-.14, \mathrm{~ns})$, while the coefficient for the relationship for women was significant and in the expected direction $(B=.28, p=.007)$. In other words, larger startle in response to viewing lesbian couples (more negative objective response) was positively associated with higher ratings of negative affect (more negative subjective response). The pattern of findings was the same for gay male stimuli. Interestingly, the discordance here was actually for men, who showed no relationship between subjective valence and objective response (as measured by startle eye blink) in any of the three sexual stimuli categories.

We also conducted two additional regression analyses to determine the relationship between social distance and subjective affective valence. A main effect was found for the relationship between social distance toward gay men and reported valence while viewing images of gay men $(B=.27, p<.0001)$ such that the more discomfort one has around gay men, the more negative their reported affect while viewing images of gay men, over and above sex of participant. The same effect was found for lesbian stimuli $(B=.21, p<.05)$ such that the more discomfort one has around lesbians, the more negative their reported affect while viewing images of lesbians, over and above sex of participant. There were however no significant sex differences with regard to these relationships.

\footnotetext{
${ }^{4}$ We thank an anonymous reviewer for suggesting that we investigate this possibility.
} 


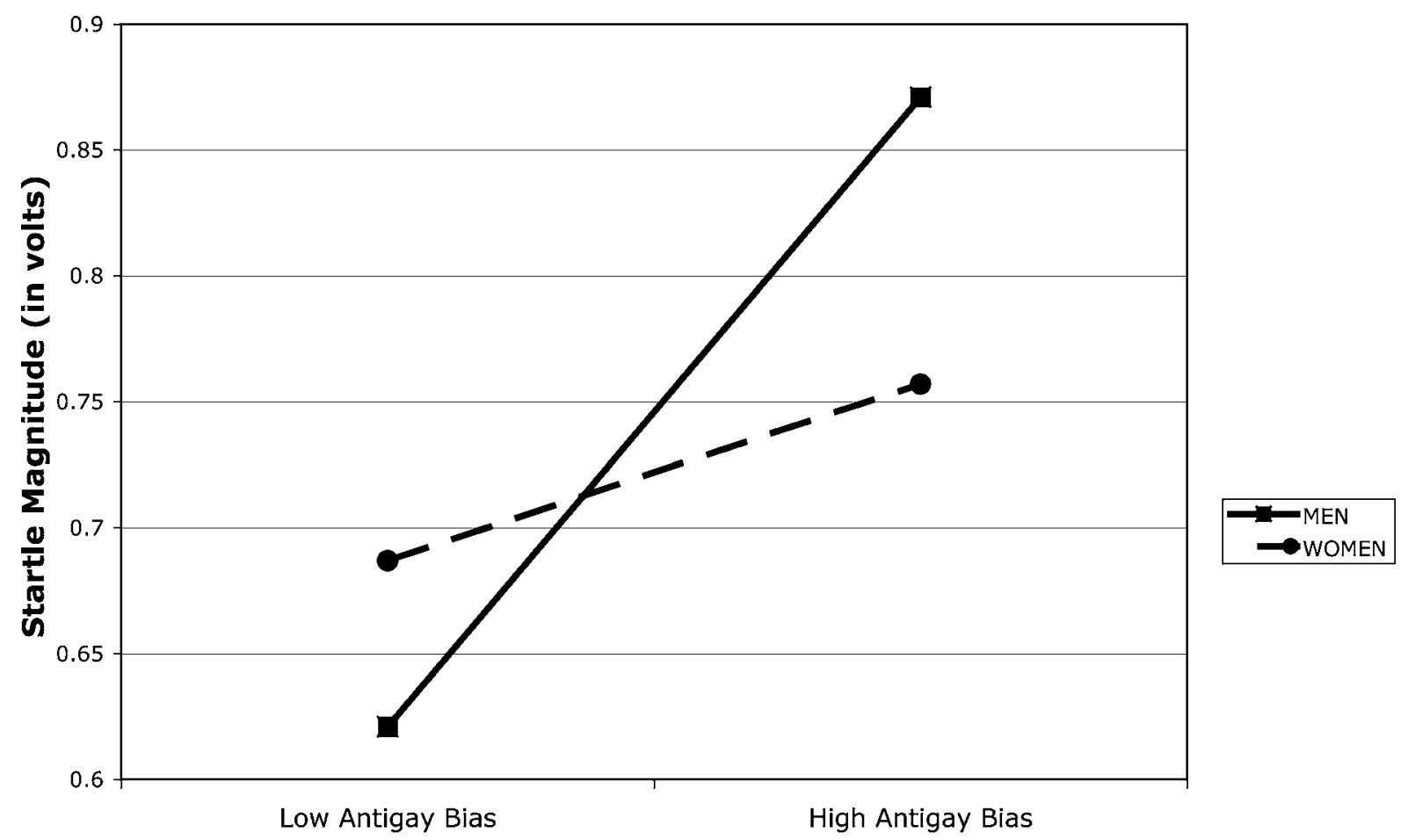

Same Sex Antigay Bias

Fig. 1. The interaction of antigay bias and sex of participant in predicting startle magnitude toward same-sex homosexual targets. There is a significant relationship between antigay bias and startle toward same-sex homosexual targets for men $(B=.13, p=.02)$ but not for women $(B=.01, \mathrm{~ns})$.

\section{DISCUSSION}

The purpose of the current study was to examine the consistent sex difference in antigay bias on a physiological level. Specifically, we exposed male and female participants to homoerotic images accompanied by a startle-eliciting burst of static. Participants' startle magnitude was then compared to their scores on a measure of social distance with regard to gay men and lesbians. While both men and women expressed more bias against same-sex targets than toward opposite-sex targets, men expressed more discomfort around gay men than women did around lesbians. Male participants also exhibited this bias physiologically. Over and above other contributing variables, being a man and espousing explicit antigay bias, as well as the interaction of the two, rendered a participant more likely to have a negative physiological reaction toward images of gay men. The results of the current study are in accord with an expanding body of evidence that supports the idea that men experience a physiological manifestation of antigay bias (e.g., Adams et al., 1996; Mahaffey et al., 2005; Shields \& Harriman, 1984), but women do not.
The general pattern of startle responses introduces an interesting question regarding emotional differences and similarities between men and women. The patterns of means were similar for both sexes in that each sex had the least startle magnitude (i.e., felt most positively) toward lesbian and heterosexual images, with images of gay men eliciting slightly larger startle responses, with neutral images producing the largest startle magnitude (i.e., least positive response). Thus, men and women both displayed attitudes toward sexual images that were positively valenced as compared to neutral images, while images of gay men were the least desirable for both sexes. Further, women displayed greater startle magnitude in every category than did men (though not to a significant degree), which is consistent with other research involving startle eye blink (Kofler, Mueller, Reggiani, \& Valls-Sole, 2001).

This sex difference may have played a role in our finding of no main effect of sex on startle eye blink patterns. Given prior research that women show less antigay bias than do men, one might have expected to at least see a sex difference in startle toward gay men, such that men produced larger (i.e., more negative) startle 
responses. It is perhaps women's overall larger startle response that may have obscured this difference or it may be the case that men and women react in the same way affectively, generally speaking, to sexual images. This is clearly an area ripe for future investigation of sex differences in responses to visual erotic stimuli. What is important, and what is most relevant to our hypotheses, is that these affective reactions were related to the expression of antigay attitudes in men but not in women, suggesting that a negative affective reaction to images of gay men is associated with cognitive biases against homosexuals among antigay-biased men, but not among less-biased men or among women.

It is interesting to note that although men showed a relationship between implicit and explicit antigay bias while women did not, it was the men who showed a disjunction between their subjective and objective affective response to sexual stimuli. With the exception of heterosexual stimuli, women showed a clear connection between their subjective appraisal of their emotions and their physiological manifestations of those emotions in the context of reactions to erotic images of gay male or lesbian couples. Our original idea was that for men, the affective component of antigay bias may be an unconscious process and, in fact, the subjective data showed that this might be the case.

This study was not designed to definitively determine the underlying reasons for sex differences in antigay bias. It does, however, lay the groundwork for future explorations of this phenomenon using startle eye blink methodology. It appears that men not only hold more negative cognitive beliefs (i.e., stereotypes) about gay men and tend to engage in more prejudicial behavior toward them (i.e., gay bashing), but our data support that some men also experience an automatic negative affective reaction at the sight of a gay couple. Women, on the whole, experience these biases to a much lesser degree. Even the women in our sample who self-reported that they would be relatively uncomfortable in close proximity to a lesbian still did not display this bias physiologically to the extent that men did.

The results of the current study were consistent with the general consensus in the literature that heterosexual men tend to hold greater prejudice toward homosexuals than heterosexual women do. It is also apparent in this study that this difference holds true even when participant and target sex are matched. Thus, it is possible that, as Whitley (2001) purported, these differences might be attributed to gender-role beliefs and men's adherence to traditional gender roles in order to maintain social status. Since men are thought to have more to lose by violating and more to gain by adhering to traditional gender norms, they tend to place more importance on upholding these norms. Since gay men are seen as being in violation of traditional gender norms, their mere existence is perceived as a threat to the preservation of those norms. It is also possible that as Kimmel (1997) suggests, homophobia is simply a necessary component of being a "real man." One final possibility is that additional, possibly unconscious factors play a role in men's antigay bias, but further research is necessary to determine what such factors would be.

The generalizability of the current study is, of course, limited in that university freshmen, of mostly Caucasian ethnicity, and presumably moderate to high socioeconomic background, comprised our participant population. Since this is a typical limitation of this type of experimental psychological research, our results are at least comparable to most other studies in this area. Another limitation is that we were unable to counterbalance the paper-and-pencil and physiological portions of this study due to the nature of the stimuli and its associated demand characteristics.

Further research is necessary to determine the bases for the sex differences in antigay bias, to separate potential automatic versus controlled biases, and to begin to determine the extent to which these are learned versus innate. Since the vast majority of research to date has either been conducted with exclusively male participants, or has simply demonstrated mean differences in antigay bias by sex, the exploration of the etiology of this difference is really in its infancy. Studies examining physiological factors, affective factors, underlying psychological factors, as well as developmental, social, and cultural factors for this difference are all crucial for understanding this complex sexual prejudice.

\section{ACKNOWLEDGMENT}

This study was supported by a Predoctoral Fellowship from the National Institute of Child Health and Human Development awarded to the first author (F31 HD 043899 01). The authors would like to thank Charles Judd, Tiffany Ito, and three anonymous reviewers for their helpful comments on an earlier draft of this paper. The authors would also like to thank Erica Sandman, Heather Lau, Barbara Banas, and Erin Langner for their assistance in data collection.

\section{REFERENCES}

Adams, H. E., Wright, L. W., \& Lohr, B. A. (1996). Is antigay bias associated with homosexual arousal? Journal of Abnormal Psychology, 105, 440-445. 
Amodio, D. M., Harmon-Jones, E., \& Devine, P. G. (2003). Individual differences in the activation and control of affective race bias as assessed by startle eyeblink responses and self-report. Journal of Personality and Social Psychology, 84, 738-753.

Blascovich, J. (2000). Psychophysiological methods. In H. T. Reis \& C. M. Judd (Eds.), Handbook of research methods in social and personality psychology (pp. 117-137). Cambridge, England: Cambridge University Press.

Brody, S., Laan, E., \& van Lunsen, R. H. (2003). Concordance between women's physiological and subjective sexual arousal is associated with consistency of orgasm during intercourse but not other sexual behavior. Journal of Sex \& Marital Therapy, 29, 15-23.

Center for the Psychophysiological Study of Emotion and Attention. (1994). The International Affective Picture System. Gainesville, FL: Center for Research in Psychophysiology, University of Florida.

Gentry, G. S. (1986). Development of scales measuring social distance toward male and female homosexuals. Journal of Homosexuality, $13,75-82$.

Clore, G. L., LeDoux, J. E., Zajonc, R. B., Davidson, R. J., \& Ekman, P. (1994). Can emotions be nonconscious? In P. Ekman \& R. J. Davidson (Eds.), The nature of emotion: Fundamental questions (pp. 283-299). New York: Oxford University Press.

Hamm, A. O., Cuthbert, B. N., Globisch, J., \& Vaitl, D. (1997). Fear and the startle reflex: Blink modulation and autonomic response patterns in animal and mutilation fearful subjects. Psychophysiology, 34, 97-107.

Hansen, G. L. (1982). Androgyny, sex-role orientation, and homosexism. Journal of Psychology, 112, 39-40.

Herek, G. M. (1987). Can functions be measured? A new perspective on the functional approach to attitudes. Social Psychology Quarterly, $50,285-303$

Herek, G. M. (1988). Heterosexuals' attitudes toward lesbians and gay men: Correlates and gender differences. Journal of Sex Research, $25,451-477$

Herek, G. M., \& Capitanio, J. P. (1999). Sex differences in how heterosexuals think about lesbians and gay men: Evidence form survey context effects. Journal of Sex Research, 36, 348-360.

Hudson, W. W. \& Ricketts, W. A. (1980). A strategy for the measurement of homophobia. Journal of Homosexuality, 5, 357-372.

Johnson, M. E., Brems, C., \& Alford-Keating, P. (1997). Personality correlates of antigay bias. Journal of Homosexuality, 34, 57-69.

Kimmel, M. S. (1997). Masculinity as homophobia: Fear, shame, and silence in the construction of gender identity. In M. M. Gergen \& S. N. Davis (Eds). Toward a new psychology of gender (pp. 223-242). Florence, KY: Taylor \& Frances/Routledge.

Kinsey, A. C., Pomeroy, W. B., \& Martin, C. E. (1948). Sexual behavior in the human male. Philadelphia: Saunders.

Kite, M. E., \& Whitley, B. E. (1998). Do heterosexual women and men differ in their attitude toward homosexuality? A conceptual and methodological analysis. In G. M. Herek (Ed.), Stigma and sexual orientation: Understanding prejudice against lesbians, gay men, and bisexuals (pp. 1-23). Newbury Park, CA: Sage.

Kofler, M., Mueller, J., Reggiani, L., \& Valls-Sole, J. (2001). Influence of gender on auditory startle responses. Brain Research, 921, 206210 .

Koukounas, E., \& McCabe, M. P. (2001). Sexual and emotional variables influencing sexual response to erotica: a psychophysiological investigation. Archives of Sexual Behavior, 30, 393-408.

Koukounas, E., \& Over, R. (2000). Changes in the magnitude of the eyeblink startle response during habituation of sexual arousal. Behaviour Research and Therapy, 38, 573-584.

Kunkel, L. E., \& Temple, L. L. (1992). Attitudes towards AIDS and homosexuals: Gender, marital status, and religion. Journal of Applied Social Psychology, 22, 1030-1040.

Kyes, K. B., \& Tumbelaka, L. (1993). Comparison of Indonesian and American college students' attitudes toward homosexuality. Psychological Reports, 74, 227-237.

Lang, P. J. (1995). The emotion probe: Studies of motivation and attention. American Psychologist, 50, 372-385.

Larsen, K. S., Reed, M., \& Hoffman, S. (1980). Attitudes of heterosexuals toward homosexuality: A Likert-type scale and construct validity. Journal of Sex Research, 16, 245-257.

Mahaffey, A. L., Bryan, A., \& Hutchison, K. E. (2005). Using startle eye blink to measure the affective component of antigay bias. Basic and Applied Social Psychology, 27, 37-45.

Mosher, D. L., \& Sirkin, M. (1984). Measuring a macho personality constellation. Journal of Research in Personality, 20, 77-94.

Sabatinelli, D., Bradley, M. M., Cuthbert, B. N., \& Lang, P. J. (1996). Wait and see: Aversion and activation in anticipation and perception. Psychophysiology, 33(Suppl. 1), S72.

Shields, S. A., \& Harriman, R. E. (1984). Fear of male homosexuality: Cardiac responses of low and high homonegative males. Journal of Homosexuality, 10, 53-67.

Spence, J. T., \& Hahn, E. D. (1997). The attitudes toward women scale and attitude change in college students. Psychology of Women Quarterly, 21, 17-34.

Twenge, J. M. (1997). Attitudes toward women, 1970-1995: A metaanalysis. Psychology of Women Quarterly, 21, 35-51.

Van de Ven, P., Bornholt, L., \& Bailey, M. (1996). Measuring cognitive, affective, and behavioral components of homophobic reaction. Archives of Sexual Behavior, 25, 155-179.

Weinberg, G. (1973). Society and the healthy homosexual. Garden City, NY: Anchor Books.

Whitley, B. E. (2001). Gender role variables and attitudes toward homosexuality. Sex Roles, 45, 691-721

Yang, A. (1998). From wrongs to rights: Public opinion on gay and lesbian Americans moves toward equality. Washington, DC: National Gay and Lesbian Task Force Policy Institute. 